\title{
Investigation on the damage of Asphalt Pavement of Urban and its solutions
}

\author{
Mandula \\ Transportation Institute, Inner Mongolia University, Hohhot, China \\ 1592673507@qq.com
}

Keywords: urban road, asphalt pavement, damage types, analysis

Abstract: With the development of local economy, the increase of urban population and the poor infrastructure in old urban area can't meet the development of the modern city. Small and medium-sized city traffic problems have gradually become the negative factors which hinder and restrict the city social economy development. As viewed from Hohhot, this article mainly aims at the urban road asphalt pavement damage condition, analyses the main damage types and puts forward to the renovation and maintenance programs.

\section{Introduction}

The city of Hohhot is located in TuMoChuan Plain which in the central of China's northern Inner Mongolia Autonomous Region, belongs to the seasonal frozen region[1]. With the rapid growth of economy, the urban traffic volumes increase year by year. Most of urban roads have varying degrees of damage under great traffic pressure. Especially the natural gas replacement, water supply, heating and other city infrastructure construction projects are relatively concentrated lead to the traffic volumes increase abruptly. Besides of the unique climate of Hohhot that cold in winter and warm in spring, the urban roads easily appear the frost boiling of subgrade, pavement cracks, loose, deformation and other different types of damages[2].

The urban road diseases not only increase the operation time and cost, but also require the traffic department puts out a lot of money to maintenance every year. Therefore, for the city road diseases, carrying on the investigation into the cause of the disease breakage, researching, proposing the practical and feasible renovation and maintenance programs to improve the road quality, prolong road service life, truly achieve the idea that "giving priority to prevention, combining prevention with treat", appear particularly important[3].

\section{The investigation object}

The roads which investigated into the asphalt pavement damages are located in the core area in Hohhot, involved 16 roads which located in Xincheng District, Saihan District, Huimin District, Yuquan District, the total length is $70.336 \mathrm{~km}$. The investigation roads have shown in Tab1. 
Tab1. The investigation roads

\begin{tabular}{|c|c|c|c|c|c|c|}
\hline \multirow{2}{*}{ No } & \multirow{2}{*}{ Road Name } & \multirow{2}{*}{$\begin{array}{l}\text { Total } \\
\text { Length }\end{array}$} & Road & \multirow{2}{*}{ Length } & \multirow{2}{*}{$\begin{array}{l}\text { Boundary } \\
\text { Lines Width }\end{array}$} & \multirow{2}{*}{ District } \\
\hline & & & Starting Point $\sim$ Terminal point & & & \\
\hline \multirow[b]{2}{*}{1} & \multirow[b]{2}{*}{ Xinhua Street } & \multirow[b]{2}{*}{6265} & Tondao Rd $\sim$ Bayannaoer Rd & 2244 & 50 & Xincheng \\
\hline & & & $\begin{array}{c}\text { Bayannaoer Rd } \sim \text { Western 2nd } \\
\text { Ring Rd } \\
\end{array}$ & 4021 & 50 & Huimin \\
\hline \multirow{2}{*}{2} & \multirow{2}{*}{ Daxue Rd } & \multirow{2}{*}{9744} & Hulun $\mathrm{Rd} \sim$ Esatern 2 nd Ring $\mathrm{Rd}$ & 5440 & 40 & Saihan \\
\hline & & & Xiling $\mathrm{Rd} \sim$ Bayan $\mathrm{Rd}$ & 4304 & 40 & Saihan \\
\hline \multirow[b]{2}{*}{3} & \multirow{2}{*}{ Zhaowuda Rd } & \multirow{2}{*}{4435} & Hailaer $\mathrm{Rd} \sim$ Qincheng $\mathrm{Rd}$ & 1031 & 40 & Xincheng \\
\hline & & & $\begin{array}{c}\text { Wulanchabu Street } \sim \text { Southern 2nd } \\
\text { Ring Rd }\end{array}$ & 3404 & 40 & Saihan \\
\hline \multirow[b]{2}{*}{4} & \multirow{2}{*}{$\begin{array}{l}\text { Xiling Nan bei } \\
\text { Rd }\end{array}$} & \multirow[b]{2}{*}{5351} & Station $\sim$ Erdos Street & 3668 & 50 & Huimin \\
\hline & & & $\begin{array}{c}\text { Erdos Street } \sim \text { Southern } \\
\text { Rd }\end{array}$ & 1683 & 50 & Yuquan \\
\hline 5 & Bayan Rd & 3540 & Erdos Street $\sim$ Hailaer Rd & 3540 & 40 & Huimin \\
\hline 6 & Hailaer Rd & 11731 & $\begin{array}{l}\text { Renhe community } \sim \text { Western 2nd } \\
\text { Ring Rd }\end{array}$ & 11731 & 50 & Xincheng \\
\hline 7 & Guangmin Street & 3380 & Bayan $\mathrm{Rd} \sim$ Xiling Rd & 3380 & 30 & Huimin \\
\hline 8 & Beihen Street & 6527 & Hulun $\mathrm{Rd} \sim$ Tenfei Rd & 6527 & 30 & Xincheng \\
\hline 9 & $\begin{array}{c}\text { Chezhan Don Xi } \\
\text { Street } \\
\end{array}$ & 1724 & Tondao $\mathrm{Rd} \sim$ Hulun $\mathrm{Rd}$ & 1724 & 30 & Xincheng \\
\hline 10 & Tondao Rd & 2381 & Chezhan Xi Street $\sim$ Zhongshan Rd & 2381 & $40 / 50$ & Huimin \\
\hline 11 & Xinan Bei Rd & 6380 & Hailaer $\mathrm{Rd} \sim$ The 110 National $\mathrm{Rd}$ & 6380 & 50 & Xincheng \\
\hline \multirow{2}{*}{12} & \multirow{2}{*}{ Erdos Street } & \multirow{2}{*}{6080} & $\begin{array}{c}\text { Danan Street } \sim \text { Xishuncheng } \\
\text { IIIStreet } \\
\end{array}$ & 1050 & 50 & Yuquan \\
\hline & & & $\begin{array}{c}\text { Xishuncheng Street } \sim \text { Western 2nd } \\
\text { Ring Rd }\end{array}$ & 5030 & 50 & Yuquan \\
\hline 13 & Niu Street & 662 & $\begin{array}{c}\text { Xishuncheng Street } \sim \text { Taiping } \\
\text { Street } \\
\end{array}$ & 662 & 40 & Huimin \\
\hline 14 & Taiping Street & 423 & Taiping Xi Street $\sim$ Taiping Bridge & 423 & 40 & Huimin \\
\hline 15 & Wushijia Street & 896 & Danan Street $\sim$ Shiyangqiao Rd & 896 & 24 & Yuquan \\
\hline 16 & Guanghua Street & 817 & Xinan $\mathrm{Rd} \sim$ Donyingbei $\mathrm{Rd}$ & 817 & 24 & Xincheng \\
\hline
\end{tabular}

\section{Investigation content and method}

According to the 《Technical code of maintenance for urban road》(CJJ 36-2006) about the provisions that maintenance condition assessment[4], investigating the road conditions on site, mainly adopt the artificial data acquisition and photograph manners to record. The specific research projects including roadway, sidewalks, roadbed and drainage facilities and other facilities. Compared with the previous pavement damage condition standard maps research results[5], we conduct the data acquisition and analysis. For example, Fig.1 and Fig.2 respectively show the different degree of asphalt pavement cracks schematic diagram and the asphalt pavement alligator cracking measurement schematic diagram. 


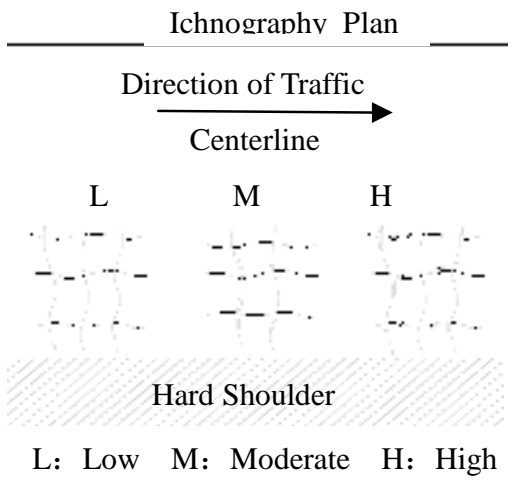

Fig.1 Different degree of asphalt pavement cracks schematic diagram

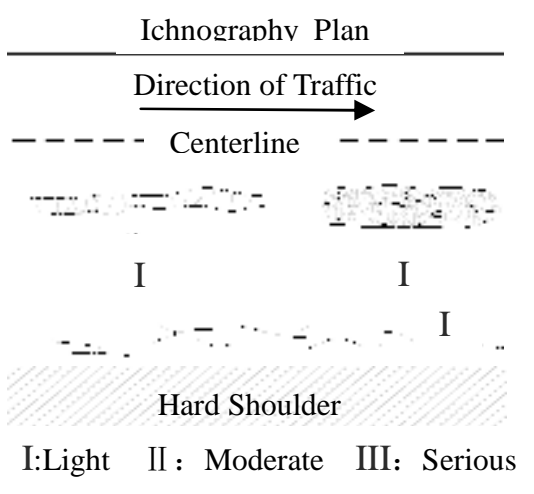

Fig.2 Asphalt pavement alligator cracking measurement schematic diagram

\section{The main pavement damages}

Through the comprehensive investigation of the mentioned roads, we find that the core area roads' pavement damages are more prominent. The damages like surface subsidence, rutting, upheaval, crack, potholes, surface voids and etc are very common and the peripheral roads located in central areas are even more prominent. Besides, the subsidence around the inspection wells, sidewalks and curbs damages also abound. The existence of these road diseases result in the reduction of roads' traffic capacity, poor traffic organization, low comprehensive service capacity of road, seriously affect the smoothness and driving comfort of the road, some even have serious impact on traffic safety. Fig. 3 shows the main seven kinds of diseases.

1) The subsidence around the inspection wells

2) Transverse cracks

3) Net-shaped cracking and alligator cracking

4) Rutting

5) Upheaval

6) Potholes

7) The inlet damage

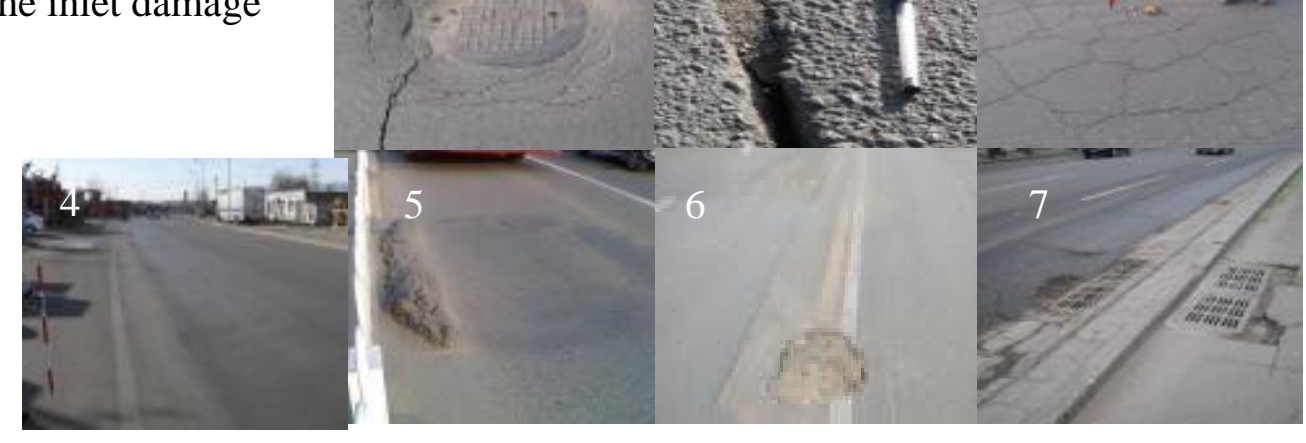

Fig.3 The main asphalt pavement diseases

\section{Analysis on the causes of diseases}

1) The subsidence around the inspection wells: Around the inspection wells, the construction of large compacting equipment is difficult, result in the degree of compaction of the road subgrade and structure layer is hard to guarantee, so cause the subsidence under the repeated traffic loading.

2) Crack: The cracks mainly are transverse cracks and with some irregular cracks and longitudinal cracks. The main reason is that with the increase of traffic volume over time lead to pavement fatigue damage so produce the structural cracks. Moreover, the large temperature difference between day and night in Hohhot, the reflection cracks caused by semi-rigid base's temperature contraction is one of reasons.

3) Rutting: Some of the roads' ruts are serious, through the field investigation we can see most of 
the ruts belong to the type of surface course instability. The main reason which produces those ruts is that the heavy-load traffic is prominent, especially in the intersection, the vehicles frequently start and park, slow running speed and long wheel load action time make the asphalt surface lose stability. Besides, due to the framework effect of the asphalt mixture is weak, the pavement easily to produce the rutting. The bad combination of the pavement courses results in the rutting exacerbated .

4) Potholes: The main reason is that water can easily infiltrate into the pavement structure through cracks, the asphalt is peeled off after the loss of the cohesive force between asphalt and aggregate, under the repeated action of vehicle load and water, the potholes form.

5) Upheaval and Subsidence: Pavement subsidence mainly due to the compression of the subgrade soil under the action of the wheel load, both sides of the subsidence often accompanied with the upheaval.

\section{The renovation and disposal program}

1) Pavement structure: In order to improve the pavement performance and prolong service life, we suggest using the SBS modified asphalt concrete and using the basalt as aggregate in this dispose process. The application of SBS modified asphalt concrete in the city's renovation projects in 2010 has achieved good effect. According to the extent of road's damage, taking reinforcement, reconstruction and etc different treatment program for the base course. When determining the renovation program, should follow the principle of less disturbing the stabilized and close-grained soubise, under layer and soil basis thus achieving the effect of good construction quality and short construction period.

2) Reinforce of the inspection wells: In order to avoid the insufficient compactions of the inspection wells, producing the subsidence, we suggest reinforcing the various types of inspection wells within the scope of driveway in this renovation and dispose process to improve the driving comfort and prolong the service life. The manhole covers of inspection well use the "five- prevent" manhole covers.

3) The dispose of intersection: It is easily produce rutting in the intersection due to the vehicles frequently park, to solve this problem, the lane of intersection entrance use the structure of "cement concrete + asphalt concrete". That is the base course use rolled cement concrete and the geogrids are overspread on the base course. The surface course use SBS modified asphalt concrete to reduce the permanent deformation of structure layer materials under the repeated action of wheel load. For the conditioned intersections should broaden the width of right-hand lane. Moreover, for the big intersection that transformed from roundabout, should adopt the design of channelization to diverge the cars and pedestrians within the scope of the intersection. The big intersections which need to be disposed mainly include the intersection of Bayan Road and Guangming Street, the intersection of Xinhua Street and Bayan Road, the intersection of Hailar Road and Xinan Road and the intersection of Hailar Road and Bayan Road.

4) Sidewalk design: The sidewalk adopts stone brick or concrete brick according to the function and importance of the road. The specification and style of brick should be selected according to the characteristics of each road.

5) Others

(1) If the existing cross slope of road which through rebuilding or broadening can't meet the design requirements, then should mill the original pavement and re-regulate the new cross slope.

(2) For those roads that sidewalks are wide and non-motorized vehicle traffic volumes are not large, pedestrians and non-motorized vehicles should share one lane to make vehicles and 
non-motorized vehicles diverge.

(3) Under the premise of reducing the impact of normal driving traffic stream, as reasonable as possible to set the bus bay stop and taxi bay stop.

\section{Conclusions}

In this investigation, the asphalt pavement roads mainly located in the core area in Hohhot, based on the relevant provisions of 《Technical code of maintenance for urban road》(CJJ 36-2006) and the previous pavement damage condition standard maps research results, conducting the data acquisition and analysis. The results show that the main diseases of roadway are crack, potholes, rutting, subsidence and the main diseases of sidewalk are the lack of preformed units, subsidence, blow up, faulting of slab ends and potholes. At the same time, we put forward to the renovation program or treatment suggestion.

\section{References}

[1] Li Xichang, Bai Meilan, Ma Yufeng, etc. Simulating the Influence of Urban Development on Atmospheric Environment in Hohhot City [J]. Meteorological Monthly. 2011, 37 (12): 1572-1577.

[2] Cheng Peifeng, Fan Yongqiang, Zhang Zhihua. Disease Investigation and Analysis of Harbin Urban Road [J].Low Temperature Architecture Technology. 2011, (6): 28-30.

[3] Zhang Yi. The Evaluation on Environment Effect of Urban Traffic Network [D]. Changsha: Hunan University Library. 2006

[4] Technical code of maintenance for urban road (CJJ 36-2006) [S].Beijing: China Architecture Building Press. 2006

[5] Ren Yan. Technology Study on Standard Atlas of Pavement Distress [D].Xian: Changan University Library.2008. 